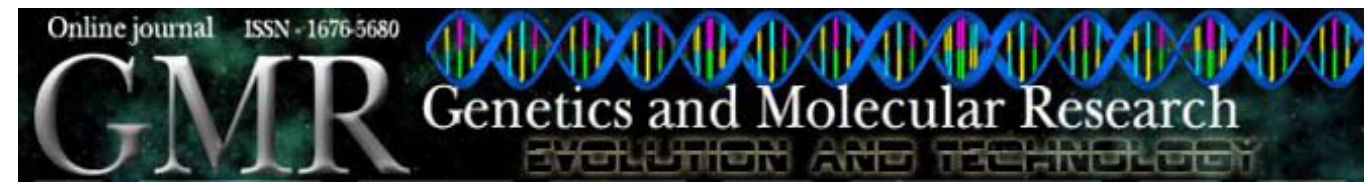

\title{
Induction of mitotic crossing-over in diploid strains of Aspergillus nidulans using low-dose $\mathrm{X}$-rays
}

L.B. Stoll ${ }^{1}$, F.C.A. Cremonesi ${ }^{2}$, L.T.A. Pires ${ }^{3}$, T.D. Zucchi ${ }^{4}$ and

T.M.A.D. Zucchi ${ }^{4,5}$

${ }^{1}$ Faculdade de Odontologia, Universidade de Franca, Franca, SP, Brasil

${ }^{2}$ Faculdade de Odontologia, Universidade de São Paulo,

Ribeirão Preto, SP, Brasil

${ }^{3}$ Centro Universitário Moura Lacerda, Ribeirão Preto, SP, Brasil

${ }^{4}$ Departamento de Parasitologia, Instituto de Ciências Biomédicas and

Centro de Pesquisas em Biotecnologia, Universidade de São Paulo,

São Paulo, SP, Brasil

${ }^{5}$ Departamento de Ciências Biológicas and Biotecnologia,

Universidade do Estado de São Paulo, Assis, SP, Brasil

Corresponding author: T.M.A.D. Zucchi

E-mail: tdzucchi@terra.com.br

Genet. Mol. Res. 7 (2): 467-475 (2008)

Received March 25, 2008

Accepted May 9, 2008

Published June 3, 2008

\begin{abstract}
As a contribution towards detecting the genetic effects of low doses of genotoxic physical agents, this paper deals with the consequences of low-dose X-rays in the Aspergillus nidulans genome. The irradiation doses studied were those commonly used in dental clinics (1-5 cGy). Even very low doses promoted increased mitotic crossing-over frequencies in diploid strains heterozygous for several genetic markers including the ones involved in DNA repair and recombination mechanisms. Genetic markers of several heterozygous strains were individu-
\end{abstract}


ally analyzed disclosing that some markers were especially sensitive to the treatments. These markers should be chosen as bio-indicators in the homozygotization index assay to better detect the recombinogenic/ carcinogenic genomic effects of low-dose X-rays.

Key words: Low-dose X-rays; Mitotic crossing-over; Aspergillus nidulans; Genotoxicity tests; DNA damage; Homozygotization index assay

\section{INTRODUCTION}

Endogenous and exogenous agents can promote DNA damage, and cell reactions can appear according to the activity of several pathways of DNA repair resulting in increased mutation and mitotic crossing-over rates (Beljanski et al., 2004). Since such biological reactions indicate DNA damage, they can be useful in detecting carcinogenic and mutagenic effects (Hollstein et al., 1979; Zeiger, 1998).

$\mathrm{X}$-ray genotoxicity is related to several DNA alterations such as double-strand breaks, single-strand breaks, casual base substitutions, deletions, induction of mitotic crossing-over, etc. (Bohr et al., 1989; Hutchinson, 1989; Bothwell et al., 2000; Rothkamm and Löbrich, 2003). Despite the extensive use of low X-ray doses in medicine and dentistry, the majority of related studies deal with high dose effects, although there is evidence that low doses promote modifications in the genetic material. Indeed, an increased occurrence of cancer after intrauterine X-ray diagnosis using doses of approximately $2 \mathrm{cGy}$ has been detected (Modan, 1992). In addition, it was suggested that in human lymphoblasts, doses below 10 cGy can be mutagenic (Grosovsky and Little, 1985; Cramers et al., 2005). Currently, only a few genetic end-points or biological markers are available to detect radiation doses close to or below $2 \mathrm{cGy}$. Therefore, considering that the above-mentioned practices are common in clinics, it is important to learn more about the genotoxic effects of X-rays at low doses, and the associated cumulative effects arising after successive low-dose treatments.

Mitotic crossing-over detection, frequently associated with loss of heterozygosity (Young et al., 2006), is especially important because of its likely involvement in the sequence of events leading to tumorigenesis (Wang et al., 1988; Imreh et al., 2003). Moreover, countless physical and chemical agents, most of which reach humans routinely, can induce mitotic crossing-over, including X-rays. After detecting increased recombination frequencies in mammalian cells after low-level X-ray exposure, Schiestl et al. (1994) asserted that recombination can be a more sensitive indicator of the biological effects of carcinogens than point mutations.

Aspergillus nidulans is adequate to study mitotic recombination because it grows normally as a haploid organism (Miyamoto et al., 2007). Moreover, under certain conditions it is possible to obtain diploid nuclei that can return to haploidy after some conditions (Chiuchetta and Castro-Prado, 2005). Thus, it is possible to treat diploid strains that can eventually recombine, and then to study the effects of such treatment in haploid strains.

An adequate and sensitive system to detect mitotic crossing-over (Pires and Zucchi, 1994) made the present approach feasible. The main aim was to observe the effect of low-dose $\mathrm{X}$-rays on the homozygotization of genes of $A$. nidulans diploid strains, originally present in the heterozygous condition. 


\section{MATERIAL AND METHODS}

\section{Aspergillus nidulans strains}

The haploid strains used were from Utrecht stocks (UT448, UT196 and UT501) or obtained in our laboratory ( $D p$ II-I), which is an uvs mutant obtained from N-methyl-N'-nitroN-nitrosoguanidine treatment of the UT448 strain (Zucchi, 1990; Castro-Prado and Zucchi, 1991a,b, 1992). Their genotypes are given in Table 1.

\begin{tabular}{|c|c|}
\hline Strain & Genotype \\
\hline UT448 & riboAl (I), pabaA124 (I), biAl (I), AcrAl (II), wA2 (II) \\
\hline UT196 & yA2 (I), methA17 (II), pyroA4 (IV) \\
\hline UT501 & pabaA110 (I), biAl (I), uvsB10 (IV) \\
\hline$D p$ II-I & $w A 2$ (II), riboAl (I), pabaA124 (I), Dp II-I (I), biAl (I), uvsA (I), AcrAl (II) \\
\hline
\end{tabular}

The diploid strains UT448 // UT196, Dp II-I // UT196 and UT501 // UT196 were prepared according to Roper's method (1952). The mutant alleles were allocated to their linkage group by mitotic haploidization (Forbes, 1959) facilitated by treatment with $p$-fluorophenylalanine ( $p$ FA) (Lhoas, 1961; Morpurgo, 1961).

\section{Culture media}

The minimum medium (MM) was Czapeck-Dox with $1 \%$ (w/v) glucose. Complete medium (CM) was as described in Zucchi $(1990,1992)$. Solid media contained 1.2\% agar. Selective medium (SM) was MM plus requirements needed by the particular strains.

\section{Procedures}

Saline conidial suspensions of the three diploids were individually prepared in test tubes, at a $1.0 \times 10^{7}$ conidia/mL concentration. The tubes were successively irradiated with Xray doses of $0.2 \mathrm{~s}$ each, until a total of $1.0 \mathrm{~s}$; five independent treatments were performed. After each $0.2 \mathrm{~s}$ of X-ray irradiation, $0.1-\mathrm{mL}$ samples were pipetted, diluted and plated on solid MM. After growing at $37^{\circ} \mathrm{C}$ for 3 days, the colonies were transferred to four positions of MM plates. Visible diploid sectors $(2 \mathrm{n})$ arising from each colony were probably recombinant diploids. Each haploid sector was individually transferred to four points of $\mathrm{CM}+p \mathrm{FA}(0.035 \mathrm{mg} / \mathrm{mL}$ plates) to be haploidized. The plates were incubated again for $4-5$ days at $37^{\circ} \mathrm{C}$ until colored haploid sectors were visible. In order to determine their genotypes, conidia from the edge of those haploid sectors were transferred to 25 defined positions ( $5 \times 5$ pattern) of CM plates and incubated for $48 \mathrm{~h}$ and then replicated to the following SM (MM plus $1 \mu \mathrm{g} / \mathrm{mL}$ riboflavin, 0.7 $\mu \mathrm{g} / \mathrm{mL} p$-aminobenzoic acid, $0.02 \mu \mathrm{g} / \mathrm{mL}$ biotin, $0.5 \mu \mathrm{g} / \mathrm{mL}$ pyridoxine), SM lacking individu- 
ally riboflavin, $p$-aminobenzoic acid, biotin and pyridoxine, and SM plus acriflavine $(62 \mu \mathrm{g} /$ $\mathrm{mL}$ ). After 48 -h incubation at $37^{\circ} \mathrm{C}$, the genotypes of the haploid segregants were determined and the frequency of mitotic crossing-over was then determined.

\section{Homozygotization index evaluation (Pires and Zucchi, 1994)}

The frequency of mitotic crossing-over was determined through the calculation of the homozygotization index (HI). The homozygotization of genes originally present in the heterozygous condition in the diploid strains was determined according to Pires and Zucchi (1994).

Mitotic crossing-over promotes the homozygotization of genes initially in heterozygosis. After mitotic crossing-over between one gene and the centromere, four types of diploids $(+/+,+/-,-/+$, and -/-) should appear, irrespective of the focused gene. Since growth following X-irradiation proceeds during growth on MM, homozygous diploids (-/-) for nutritional recessive markers were counter selected. In this way, only those $+/+,+/-$ and $-/+$ diploids are selected and transferred to $\mathrm{CM}$ plus $p \mathrm{FA}$ in order to be haploidized. Consequently, the counter selection of diploids bearing markers homozygous (-/-) for one or more auxotrophic markers results in distortions of segregation rates, which is detected by, e.g., the 4+ / 2- $(=2)$ rates, as opposed to the expected 4+ / 4- $(=1)$.

The HI determined for any auxotrophic marker of a heterozygous diploid cell, after only one crossing-over event, is $2.0(\mathrm{HI}=\%+/ \%-)$ (Pires and Zucchi, 1994). Therefore, HI values higher than 2.0 should indicate the occurrence of mitotic crossing-over events (for the given marker) in a larger number of diploid cells. Thus, the higher the proportion of mitotic crossing-over between one auxotrophic marker and the centromere, the higher the HI of the markers will be. This index is an indirect way to evaluate the frequency of mitotic crossingover. It is important to mention that the diploid strains used here bear several auxotrophic markers in heterozygous configuration and the homozygotization of each one independently prevents the growth of the recombinant diploids in the MM. The higher the number of heterozygous auxotrophic markers in the chosen diploid strain, the higher its sensitivity should be in detecting recombinogenic agents.

\section{X-ray treatment}

The X-ray equipment used followed the pattern currently employed in dental clinics $(10 \mathrm{~mA} ; 70 \mathrm{kVp})$. The distance from the source to the tube containing the conidial suspension was $20.0 \mathrm{~cm}$. The estimated applied dose was $1.0 \mathrm{cGy}$ for each exposure of $0.2 \mathrm{~s}$.

\section{RESULTS}

For each X-ray treatment of the original diploid strains (UT448 // UT196, Dp II-I // UT196 and UT501 // UT196), 6-8 recombinant diploids were haploidized, and after mitotic analysis the HI was calculated. For the three diploid strains studied, Table 2 shows the number of haploids analyzed after each treatment and their respective HI average (an HI was calculated for each recombinant diploid; data not shown). For the three original diploid strains, Figure 1 illustrates the maximum $\mathrm{HI}$ in comparison to control values. 


\begin{tabular}{|c|c|c|c|c|c|c|}
\hline \multicolumn{7}{|l|}{$\mathbf{A}$} \\
\hline & \multirow[t]{2}{*}{ Haploids analyzed } & \multicolumn{5}{|c|}{ HI UT448 // UT196 (genetic markers) } \\
\hline & & ribo & paba & $b i$ & meth & pyro \\
\hline Control & 45 & 2.2 & 1.5 & 2.1 & 2.5 & 2.1 \\
\hline $0.2{ }^{\prime}$ & 14 & 3.3 & 0.0 & 3.3 & 5.5 & 5.5 \\
\hline $0.4{ }^{\prime}$ & 5 & 4.0 & 4.0 & 4.0 & 4.0 & 4.0 \\
\hline 0.6, & 11 & 2.7 & 2.7 & 2.7 & 2.7 & 2.7 \\
\hline $0.8^{\prime}$ & 19 & 8.5 & 18.0 & 18.0 & 17.7 & 1.4 \\
\hline $1.0 "$ & 41 & 0.9 & 1.3 & 1.3 & 2.5 & 2.0 \\
\hline \multicolumn{7}{|l|}{$\mathbf{B}$} \\
\hline & \multirow[t]{2}{*}{ Haploids analyzed } & \multicolumn{5}{|c|}{ HI $D p$ II-I // UT196 (genetic markers) } \\
\hline & & ribo & paba & $b i$ & meth & pyro \\
\hline Control & 23 & 6.0 & 6.5 & 7.0 & 2.6 & 1.5 \\
\hline $0.2{ }^{\prime}$ & 15 & 15.0 & 14.0 & 14.0 & 6.5 & 4.0 \\
\hline $0.4{ }^{\prime \prime}$ & 11 & 1.2 & 1.2 & 1.2 & 1.7 & 0.5 \\
\hline $0.6^{\prime \prime}$ & 30 & 29.2 & 29.2 & 14.1 & 2.3 & 2.0 \\
\hline $0.8^{\prime \prime}$ & 35 & 17.0 & 10.5 & 17.0 & 6.0 & 3.0 \\
\hline $1.0 "$ & 21 & 9.5 & 4.5 & 9.5 & 7.5 & 6.0 \\
\hline \multicolumn{7}{|l|}{$\mathbf{C}$} \\
\hline & \multirow[t]{2}{*}{ Haploids analyzed } & \multicolumn{5}{|c|}{ HI UT501 // UT196 (genetic markers) } \\
\hline & & & paba & $b i$ & meth & pyro \\
\hline Control & 11 & & 5.0 & 5.0 & 5.0 & 5.0 \\
\hline $0.2{ }^{\prime}$ & 16 & & 7.5 & 7.5 & 7.5 & 7.5 \\
\hline $0.4^{\prime \prime}$ & 8 & & 8.0 & 6.1 & 8.0 & 6.1 \\
\hline $0.6^{\prime}$ & 11 & & 5.0 & 5.0 & 5.0 & 5.0 \\
\hline $0.8^{\prime \prime}$ & 13 & & 6.0 & 6.0 & 5.5 & 6.0 \\
\hline $1.0 "$ & 13 & & 6.0 & 6.0 & 5.5 & 6.0 \\
\hline
\end{tabular}

Color markers were not included in this analysis because the homozygotes for conidial color markers are not MM selectable (any color conidia survive on MM), and thus, there were no segregation rate distortions.

The treatments increased the $\mathrm{HI}$ values for all the genetic markers from the diploid UT448 // UT196 (Figure 1A, Table 2A) in an equivalent proportion, except for ribo and pyro.

In $D p$ II-I // UT196 diploid, the HI from genetic markers (Figure 1B) reached higher values than in the former experiment. This should be expected since $D p$ II-I is usually UVsensitive (Marin and Zucchi, 1991), and its DNA lesions can be only repaired by recombinational repair (Pires and Zucchi, 1994). Besides, it bears a DNA transposed duplication (II-I), which is responsible for its increased mitotic instability (Castro-Prado and Zucchi, 1991a,b). Two gene sets can be distinguished according to their behaviors (Figure 1B, Table 2B): one set involves ribo, paba and bi, and the other, meth and pyro. A lower dose $(0.6 \mathrm{~s})$ is enough to induce higher HI in the $D p$ II-I // UT196 as compared to the 0.8 s corresponding to the dose needed to produce similar effects in the normal diploid (UT448 // UT196). This is an excellent indication of the higher sensitivity of the $D p$ II-I // UT196 diploid strain. 
The markers of the UT501 // UT196 diploid (Figure 1C, Table 2C) respond less to the X-ray doses used. Without any X-ray treatment, this strain displayed HI values identical to those of Dp II-I // UT196, although the rates did not increase significantly in proportion to treatments. All genes involved showed similar HIs indicating that they characterized a strain defective in recombinational repair. The $u v s$ character of UT501 is probably related to such defect.
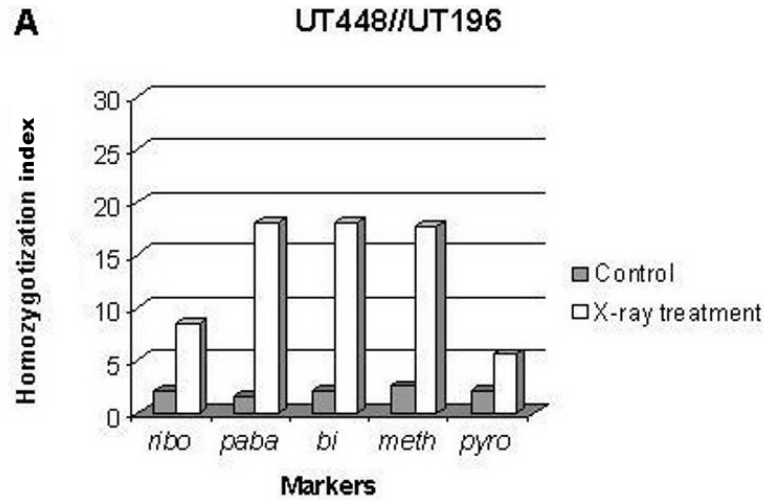

B

Dp II-I//UT196
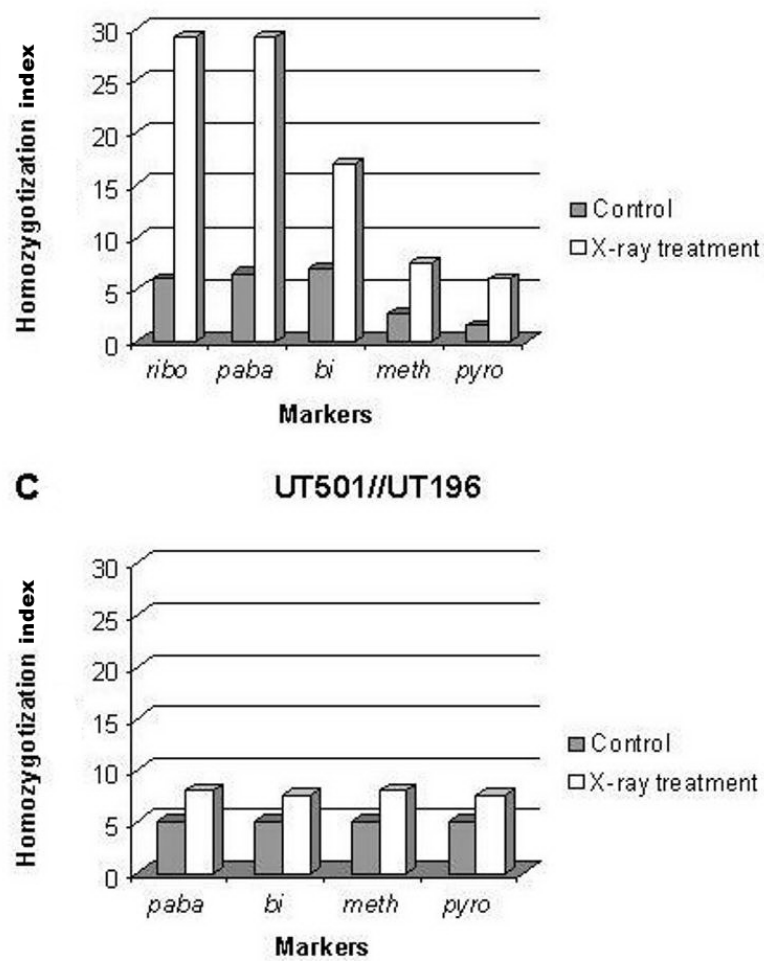

Figure 1. Maximum homozygotization index found after X-ray exposure. 


\section{DISCUSSION}

Presently, there is an increased interest towards the genetic effects associated with low-dose X-ray radiation exposure, since such low levels are almost ubiquitous in the environment as produced by several sources such as nuclear explosions, radiation accidents, medical diagnostics, therapeutics, and occupational exposures.

Mitotic crossing-over as a repair mechanism is induced by DNA damage and depends on the release of protein factors (Holliday, 1971; Bashkirov et al., 2000; Helleday, 2003). As shown here, even low doses (1.0 cGy) are capable of inducing mitotic crossing-over. Although such low doses are not enough to introduce detectable DNA damage, they are enough to induce adaptive responses in a large variety of cells (Park et al., 1999; Joiner et al., 2001; Güerci et al., 2004).

All diploid strains used in this study showed mitotic crossing-over induction reaching a maximum value and then declining. The observed peaks for each strain may change with the doses employed because the diploids used are composed of strains having different DNA repair capabilities. Such curve shape characterizes the mitotic recombination process (Ferguson, 1990). Indeed, Kunz et al. (1985) reported that curves of mitotic recombination are not linear. The non-linearity could be inherent to the recombinogenesis mechanism, as it depends on inducible components involved in the recombination process. Schiestl et al. (1994) also found such non-linearity which was attributed to the non-targeted effect of X-rays.

The three diploid strains used have their maximum recombinational responses after different cumulative doses (Figure 1); the normal diploid strain is more tolerant to cumulative low X-ray doses than those repair-deficient strains and shows lower recombination frequencies. This means that the extent of damage in DNA inflicted by X-ray is lower, and consequently, the mitotic recombination frequencies between any genetic marker and centromere are also lower than other strains used. The expected behavior of the $D p$ II-I // UT196 is to show higher HI values, on average, compared to the control and also for all the genetic markers independently. The main characteristic of the strain $D p$ II-I, due to the duplicate segment in chromosome I, is the presence of recombinational repair only. In this way, this diploid can carry out X-ray damage only by recombinational repair. Furthermore, the HI involving duplicated genes in non-homologous chromosomes yields distorted results when compared to the $\mathrm{HI}$ values from the control diploid strain. This fact explains the observed values for the control of $D p$ II-I // UT196 being similar to those values found for UT448 // UT196 after X-ray treatment (Figure 1A and B).

The UT501 // UT196 strain responds quite differently to this genotoxic treatment (Table 2C and Figure 1C). This strain behaves as defective in recombinational repair because it is unable to remove the DNA segment damaged by the X-ray treatment through induced mitotic crossing-over. In general, HI for the non-treated diploid is almost the same as that for the treated one. This means that the X-ray treatment induced lesions that did not affect mitotic recombination for lesion repair, as well in non-treated diploid. Such result suggests that this strain is unable to efficiently repair, by mitotic recombination, eventual DNA lesions, or those spontaneous damages appearing as a consequence of DNA replication. Those treated conidia very likely showed also very low viability considering this strain's DNA repair deficient mechanisms (Figure 1C).

For UT448 // UT196 and Dp II-I // UT196, the markers generally showed a clustered reaction. In UT448 // UT196 paba-bi and meth are repaired with similar efficiencies, but pyro 
and ribo with different degrees of efficiency. In $D p$ II-I // UT196, gene groups that are repaired with different efficiency are paba-bi-ribo and meth-pyro. A differential recombination frequency is suggested, which indicates that there are chromosomal regions where the occurrence of crossing-over is more frequent than in others. Such regions could be preferentially accessed by repair enzymes triggering the recombinational repair. This observation is well known in mammals, where DNA damages are removed at different efficiencies, according to the structural particularities of the DNA in certain regions of the genome, and to the preferential repair that is modulated by the extent of DNA methylation (Menichini et al., 1991; Nishant and Rao, 2006).

In this way, this study detected the effects of low X-ray doses in A. nidulans strains. The advantage of the genetic approach applied here is that it does not restrict its target to a particular locus. It measures mitotic crossing-over acting as a repair system induced by any DNA lesion in a large segment of the chromosome. The data showed clear evidence of the high sensitivity of HI assay in detecting the effects of very low X-ray doses in the eukaryotic genome.

\section{ACKNOWLEDGMENTS}

We are indebted to Prof. Hector F. Terenzi, Prof. Ronaldo Zucchi (Department of Biology, FFCL, Ribeirão Preto) and Dr. Carlos E. Winter (Department of Parasitology, ICB, São Paulo) from São Paulo University, for helpful discussions and for correcting the text. Our thanks are extended also to Mrs. Rosa Maria de Moraes and Sônia Mathias da Silva for technical assistance. Financial support from CNPq (Conselho Nacional de Desenvolvimento Científico e Tecnológico, \#5000.7590.5) and from FAPESP (Fundação de Amparo à Pesquisa do Estado de São Paulo, \#0227-1), Brazil, is acknowledged.

\section{REFERENCES}

Bashkirov VI, King JS, Bashkirova EV, Schmuckli-Maurer J, et al. (2000). DNA repair protein Rad55 is a terminal substrate of the DNA damage checkpoints. Mol. Cell Biol. 20: 4393-4404.

Beljanski V, Marzilli LG and Doetsch PW (2004). DNA damage-processing pathways involved in the eukaryotic cellular response to anticancer DNA cross-linking drugs. Mol. Pharmacol. 65: 1496-1506.

Bohr VA, Evans MK and Fornace AJ Jr (1989). DNA repair and its pathogenetic implications. Lab. Invest. 61: 143-161.

Bothwell AM, Whitehouse CA and Tawn EJ (2000). The application of FISH for chromosome aberration analysis in relation to radiation exposure. Radiat. Protec. Dosimetry 88: 7-14.

Castro-Prado MAA and Zucchi TMAD (1991a). Stabilization of a duplicated segment DP (II-I) in an uvs mutant of Aspergillus nidulans through genetic mechanisms. Rev. Bras. Genet. 14: 239-248.

Castro-Prado MAA and Zucchi TMAD (1991b). Meiotic segregation of a recessive gene $\left(w A_{2}\right)$ included in a Dp(II,I) of Aspergillus nidulans. Rev. Bras. Genet. 14: 249-260.

Castro-Prado MAA and Zucchi TMAD (1992). Characterization of the Dp(II,I) in Aspergillus nidulans: presence of AcrA and its regulatory transcription sequence in the transposed segment. Rev. Bras. Genet. 15: 777-788.

Chiuchetta SJR and Castro-Prado MAA (2005). Genotoxic evaluation of sodium nitroprusside in Aspergillus nidulans. Genet. Mol. Biol. 28: 798-803.

Cramers P, Atanasova P, Vrolijk H, Darroudi F, et al. (2005). Pre-exposure to low doses: modulation of X-ray-induced DNA damage and repair? Radiat. Res. 164: 383-390.

Ferguson LR (1990). Mutagenic and recombinogenic consequences of DNA-repair inhibition during treatment with 1,3-bis(2-chloroethyl)-1-nitrosourea in Saccharomyces cerevisiae. Mutat. Res. 241: 369-377.

Forbes E (1959). Use of mitotic segregation for assigning genes to linkage groups in Aspergillus nidulans. Heredity 13: $67-80$.

Grosovsky AJ and Little JB (1985). Evidence for linear response for the induction of mutations in human cells by X-ray exposures below 10 rads. Proc. Natl. Acad. Sci. U. S. A. 82: 2092-2095.

Güerci AM, Dulout FN and Seoane AI (2004). DNA damage in Chinese hamster cells repeatedly exposed to low doses of

Genetics and Molecular Research 7 (3): 467-475 (2008)

CFUNPEC-RP www.funpecrp.com.br 
X-rays. Cytogenet. Genome Res. 104: 173-177.

Helleday T (2003). Pathways for mitotic homologous recombination in mammalian cells. Mutat. Res. 532: 103-115.

Holliday R (1971). Biochemical measure of the time and frequency of radiation-induced allelic recombination in Ustilago. Nat. New Biol. 232: 233-236.

Hollstein M, McCann J, Angelosanto FA and Nichols WW (1979). Short-term tests for carcinogens and mutagens. Mutat. Res. 65: 133-226.

Hutchinson F (1989). Use of data from bacteria to interpret data on DNA damage processing in mammalian cells. Mutat. Res. 220: 269-278.

Imreh S, Klein G and Zabarovsky ER (2003). Search for unknown tumor-antagonizing genes. Genes Chromosomes Cancer 38: 307-321.

Joiner MC, Marples B, Lambin P, Short SC, et al. (2001). Low-dose hypersensitivity: current status and possible mechanisms. Int. J. Radiat. Oncol. Biol. Phys. 49: 379-389.

Kunz BA, Eckardt F and Haynes RH (1985). Analysis of non-linearities in frequency curves for UV-induced mitotic recombination in wild-type and excision-repair-deficient strains of yeast. Mutat. Res. 151: 235-242.

Lhoas P (1961). Mitotic haploidization by treatment of Aspergillus niger diploids with para-fluorophenylalanine. Nature 190: 744.

Marin JM and Zucchi TMAD (1991). Genetic analysis of some factors affecting mitotic and meiotic behavior of a mutant of Aspergillus nidulans. Rev. Bras. Genet. 14: 9-20.

Menichini P, Vrieling H and van Zeeland AA (1991). Strand-specific mutation spectra in repair-proficient and repairdeficient hamster cells. Mutat. Res. 251: 143-155.

Miyamoto CT, Sant'Anna JR, Franco CC and Castro-Prado MA (2007). Genotoxicity (mitotic recombination) of the cancer chemotherapeutic agents cisplatin and cytosine arabinoside in Aspergillus nidulans. Food Chem. Toxicol. 45: 1091-1095.

Modan B (1992). Low-dose radiation carcinogenesis. Eur. J. Cancer 28A: 1010-1012.

Morpurgo G (1961). Somatic segregation induced by $p$-fluoro-phenylalanine. Aspergillus News Letter 2: 10.

Nishant KT and Rao MR (2006). Molecular features of meiotic recombination hot spots. Bioessays 28: 45-56.

Park SH, Lee Y, Jeong K, Yoo SY, et al. (1999). Different induction of adaptive response to ionizing radiation in normal and neoplastic cells. Cell Biol. Toxicol. 15: 111-119.

Pires LTA and Zucchi TMAD (1994). A new method to detect potencial genotoxic agents using mitotic crossing over in diploid strains of Aspergillus nidulans. Braz. J. Genet. 17: 371-376.

Roper JA (1952). Production of heterozygous diploids in filamentous fungi. Experientia 8: 14-15.

Rothkamm K and Löbrich M (2003). Evidence for a lack of DNA double-strand break repair in human cells exposed to very low X-ray doses. Proc. Natl. Acad. Sci. U. S. A. 100: 5057-5062.

Schiestl RH, Khogali F and Carls N (1994). Reversion of the mouse pink-eyed unstable mutation induced by low doses of X-rays. Science 266: 1573-1576.

Wang YY, Maher VM, Liskay RM and McCormick JJ (1988). Carcinogens can induce homologous recombination between duplicated chromosomal sequences in mouse L cells. Mol. Cell Biol. 8: 196-202.

Young BD, Debernardi S, Lillington DM, Skoulakis S, et al. (2006). A role for mitotic recombination in leukemogenesis. Adv. Enzyme Regul. 46: 90-97.

Zeiger E (1998). Identification of rodent carcinogens and noncarcinogens using genetic toxicity tests: premises, promises, and performance. Regul. Toxicol. Pharmacol. 28: 85-95.

Zucchi TMAD (1990). Isolation of putative recombination mutants of Aspergillus nidulans. Rev. Bras. Genet. 13: 409-443.

Zucchi TMAD (1992). Another methA ${ }_{17}$ suppressor of Aspergillus nidulans. Rev. Bras. Genet. 15: 267-279. 